\title{
Associations between ambient air pollutants and hospital admissions: more needs to be done
}

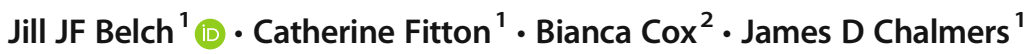 \\ Received: 18 February 2021 / Accepted: 10 September 2021 / Published online: 30 September 2021 \\ (C) The Author(s) 2021
}

\begin{abstract}
Deaths from air pollution in the UK are higher by a factor of 10 than from car crashes, 7 for drug-related deaths and 52 for murders, and yet awareness seems to be lacking in local government. We conducted an 18-year retrospective cohort study using routinely collected health care records from Ninewells Hospital, Dundee, and Perth Royal Infirmary, in Tayside, Scotland, UK, from 2000 to 2017. Hospitalisation events and deaths were linked to daily nitric oxides (NOX, NO, NO2), and particulate matter 10 (PM10) levels extracted from publicly available data over this same time period. Distributed lag models were used to estimate risk ratios for hospitalisation and mortality, adjusting for temperature, humidity, day of the week, month and public holiday. Nitric oxides and PM10 were associated with an increased risk of all hospital admissions and cardiovascular (CV) admissions on day of exposure to pollutant. This study shows a significant increase in all cause and CV hospital admissions, on high pollution days in Tayside, Scotland.
\end{abstract}

Keywords Air pollution - Cardiovascular disease $\cdot$ Hospital admissions

\section{Introduction}

Globally it is estimated that $16 \%$ of deaths are related to air pollution (Landrigan et al. 2018) with around 40,000 UK deaths/annum attributable to outdoor air pollution (Royal College of Physicians 2016) mostly from traffic. This extrapolates to 50 deaths a week occurring in Scotland (Royal College of Physicians 2016), the area of study. Air pollution plays a role in many health challenges and is projected by end 2031 to be the leading environmental cause of mortality globally (Royal College of Physicians 2016).

The general public find it difficult to believe that deaths from air pollution in the UK are 10 times that from car crashes $(1,770$ reported road deaths 2018 (National Records of Scotland 2020)), 7 times the numbers of drug-related deaths (5546 in 2018 (Office

Responsible Editor: Lotfi Aleya

Jill JF Belch

j.j.f.belch@dundee.ac.uk

Catherine Fitton

c.y.fitton@dundee.ac.uk

1 Ninewells Hospital and Medical School, Dundee DD1 9SY, UK

2 Leuven University: Katholieke Universiteit Leuven, Leuven, Belgium for National Statistics 2019; Statista 2020)) and 52 times the number of murders (701 England 2018/2019(Scottish Government 2018), 59 Scotland 2017 (Nawrot et al. 2011)). There is a frightening ignorance of the level of risk to health that occurs with air pollution, even in urban and small city regions. It is the most disadvantaged who suffer most, being frequently located near busy polluting roads.

Concentration limits for pollutants have been set by the UK and devolved governments, not by adhering to the EU Regulations (Eur-Lex 2008) but using the World Health Organization's air quality guidelines (World Health Organization Europe 2006). The current WHO value of $40 \mu \mathrm{g} / \mathrm{m} 3$ (annual mean) for nitric oxides (NO2) was set to protect the public from the health effects of gaseous NO2. The EU directive maximum level for annual values is 32 and $28 \mu \mathrm{g} / \mathrm{m} 3$ for NOx and particulate matter (PM), respectively (Butland et al. 2017). Despite both the WHO (World Health Organization Europe 2006) and EU regulations (EurLex 2008) (the latter is law), high levels of toxic pollution are still tolerated.

This study, from the Tayside Pollution Research Programme (TPRP), aims to investigate the effects of air pollution on acute hospital admissions over a 17-year period, across Tayside, Scotland, containing two of Scotland's smaller cities: Dundee (population circa 148,270) and Perth (population circa 44,820). 


\section{Materials and methods}

\section{Patient population}

A record linkage time series study of all hospital admissions at Ninewells Hospital, Dundee, and Perth Royal Infirmary, Perth, was carried out from January 1, 2000, to December 31, 2017. Consent was given by the Tayside Caldicott Guardian. As these data were anonymised, the requirement for consent to publish is not applicable.

\section{Data management}

Unique personal identifier codes $(\mathrm{CHI})$ were used to extract electronic medical records from a database for Tayside. All data storage and analyses were carried out on anonymised data, within the Safe Haven, the Tayside Health Informatics Centre (HIC), who provided the linkage of admissions to daily pollution levels across the region.

\section{Hospital admission and deaths definition}

Hospital admissions of interest were agreed a priori and were defined by ICD10 code (2016 addition), identified from the Scottish Morbidity Record 01 (SMR01) database. These were all admissions regardless of ICD10 code, relevant cardiovascular admissions (ICD10 code: selected from within I00-99). Cardiovascular $(\mathrm{CV})$ admissions were restricted to patients over 45 to exclude congenital disease. Deaths were identified from the National Records of Scotland (NRS).

\section{Exposure data}

Daily PM10 (particulate matter with a diameter $<10 \mu \mathrm{m}$ ), NOX, nitrogen dioxide (NO2) and nitric oxide (NO) concentrations were measured during the study period at the Dundee and Perth urban background sites, (part of the UK's Automatic Urban and Rural Network (AURN)). The risk of having a hospital admission or dying for each $10 \mu \mathrm{g} / \mathrm{m}^{3}$ increase in PM10, NOX, NO2 and NOx was calculated. Highest quartiles and deciles were compared to the lowest. PM2.5 $\mu \mathrm{m}$ data were excluded as these were only measured for 5 years in Dundee and not in Perth. Days with missing air pollution data were also excluded.

Because climate is a known confounder between air pollution and disease (Ye et al. 2012), data on mean air temperature and relative humidity were obtained. For temperature, data from the measuring stations Mylnefield (Lat, 56.45699; Long, -3.07182) and Dalwhinnie (Lat, 56.9333; Long, -4.2333) were used, for Dundee and Perth, respectively. Humidity data were recorded at Leuchars (Lat, 56.3833; Long, -2.8667) (8 miles distant) and were used for Dundee; for Perth, Dalwhinnie data were used.

\section{Statistical analysis}

To account for delayed effects of air pollution on ALI admissions, we combined quasi-Poisson regression with distributed lag (non-linear) models (DL(N)Ms), using separate models for PM10, NOx, NO2 and NO. DL(N)Ms enable the investigation of the temporal pattern of the association, providing an estimate of the "overall" effect of the exposure, incorporating potential delayed and harvesting effects. A DL $(\mathrm{N}) \mathrm{M}$ model is defined through a "cross-basis" function, a bi-dimensional space of functions describing simultaneously the shape of the relationship along the space of the predictor (exposureresponse function) and its distributed lag effects (lag-response function). We used a natural spline non-linear exposure-response function for the association between air pollution exposure and hospital admissions/deaths. The number of days included in the cross-basis and degrees of freedom for the natural cubic splines were chosen using a combination of qAIC and visual inspection of the 3D exposure-lag-response surfaces. An extended lag period of 0-5 days (day of exposure up to 5 days after) was used for all, CVD only, heart failure (HF) and myocardial infarction (MI) admissions, and for mortality. The lag structure was modelled with a natural cubic spline with three degrees of freedom (df), placing the knots at equally spaced values on the log scale of lags to allow more flexible lag effects at shorter delays. Categorical variables for day of the week (1-7), month (1-12) and public holidays (0 or 1) were included in the model to control for any weekly or monthly patterns in ALI admission. To account for the (potentially delayed) effects of meteorological factors on ALI admissions (36), we also included DLNM cross-bases for mean temperature and for humidity in the model. In both cross-bases, the maximum lag was set to 14 days, and natural cubic splines with five $\mathrm{df}$ were used to model the exposureresponse and the lag-response functions, respectively.

Risk ratios (RR) of hospital admissions and deaths were calculated for moderate (75th percentile) and high (95th percentile) exposure to air pollutant concentrations, compared to that of low ( 0 percentile) exposure (1s). Reported estimates, computed as the risk at day 0 (day of exposure), and the cumulative risk over the total lag period, are presented with corresponding 95\% confidence intervals $(\mathrm{CI})$.

All analyses were performed with the statistical software $\mathrm{R}$ (R Foundation for Statistical Computing, Vienna, Austria) using the "dlnm" package (https://cran.r-project.org/web/ packages/dlnm/index.html).

\section{Results}

Details about the admission breakdown and pollution levels over the study period are given in supplementary information (Tables 1s-5s, Fig 1s). Fig 2s-5s show the 3D plots and the 
Table 1 Adjusted risk ratios with 95\% confidence intervals for all hospital admissions for adults $>45 y e a r s$ and exposure to pollutants in Dundee and Perth. Lag 0 and cumulative risk (lag 0 5 days) given. Results presented as moderate (P75 vs P0) or high (P95 vs $\mathrm{P} 0$ ) exposure to a pollutant

\begin{tabular}{|c|c|c|c|c|}
\hline \multirow[t]{2}{*}{ Exposure } & \multicolumn{2}{|l|}{ Dundee } & \multicolumn{2}{|l|}{ Perth } \\
\hline & $\begin{array}{l}\text { Moderate exposure } \\
\text { (P75 vs P0) }\end{array}$ & $\begin{array}{l}\text { High exposure } \\
\text { (P95 vs P0) }\end{array}$ & $\begin{array}{l}\text { Moderate exposure } \\
\text { (P75 vs P0) }\end{array}$ & $\begin{array}{l}\text { High exposure } \\
\text { (P95 vs P0) }\end{array}$ \\
\hline \multicolumn{5}{|l|}{ Lag 0} \\
\hline PM10 & $1.103(1.052-1.157)$ & $1.127(1.074-1.182)$ & $1.388(1.267-1.521)$ & $1.438(1.315-1.572)$ \\
\hline NOX & $2.083(1.958-2.216)$ & $2.281(2.142-2.429)$ & $1.543(1.455-1.637)$ & $1.653(1.556-1.756)$ \\
\hline $\mathrm{NO} 2$ & $1.954(1.806-2.114)$ & $2.093(1.933-2.266)$ & $1.490(1.389-1.598)$ & $1.581(1.471-1.701)$ \\
\hline NO & $2.255(2.026-2.509)$ & $2.343(2.017-2.723)$ & $1.520(1.442-1.601)$ & $1.625(1.539-1.715)$ \\
\hline \multicolumn{5}{|c|}{ Cumulative } \\
\hline PM10 & $1.028(0.985-1.073)$ & $1.020(0.978-1.064)$ & $0.976(0.901-1.057)$ & $0.970(0.898-1.049)$ \\
\hline NOX & $0.953(0.910-0.998)$ & $0.956(0.913-1.001)$ & $0.946(0.902-0.989)$ & $0.941(0.897-0.989)$ \\
\hline $\mathrm{NO} 2$ & $0.976(0.918-1.037)$ & $0.973(0.915-1.035)$ & $0.957(0.905-1.013)$ & $0.959(0.904-1.018)$ \\
\hline $\mathrm{NO}$ & $0.944(0.859-1.039)$ & $0.913(0.790-1.055)$ & $0.942(0.904-0.983)$ & $0.937(0.897-0.980)$ \\
\hline
\end{tabular}

exposure-response plots for the non-linear models. Figs $2 \mathrm{~s}-5 \mathrm{~s}$ show that the models are non-linear in nature, and the slope of the association is steeper with higher concentrations. The effects are seen on day of exposure rather than over the lag period, shown by an increased RR on day 0 and a return to RR 1.00 after lag 1 (Fig 2s-3s).

Moderate (P75 vs P0 exposure) and high (P95 vs P0 exposure) exposure to all pollutants was associated with an increased risk of hospital admission for any reason in Dundee and Perth on day of exposure (Table 1). This association was not reflected following the lag period (lag 0-5). Similarly, moderate and high exposure to all pollutants was associated with an increased risk of CVD hospital admissions on day of exposure in Dundee and Perth, but not following the lag period (Table 2).

There was an association between moderate and high pollutant exposure and MI hospital admission across Dundee and Perth on day of exposure; however, results were only significant in the Perth location (Table 3). There was no clear association following the lag period. Moderate and high pollutant exposure was associated with increased HF hospital admissions on day of exposure in Dundee and Perth; however, this again was only significant for Perth (Table 4). There was also no clear association with risk of admission following the lag period.

All-cause mortality was not associated with any pollution exposure, in Dundee or Perth, for either day of exposure or cumulative exposure (Table 6s).

\section{Discussion}

This 17-year time series analysis study shows that air pollution is associated with an increase of all hospital admissions, and CVD admissions, for adults $>45$ years in two small cities in Scotland on day of exposure to pollution. We also report an association between pollution exposure with MI and HF hospital admissions, on day of exposure; however, significance was not reached for all
Table 2 Adjusted risk ratios with $95 \%$ confidence intervals for all $\mathrm{CV}$ hospital admissions of patients under $>45$ years, in Dundee and Perth and exposure to pollutants. Lag 0 and cumulative risk (lag 0-5 days) given. Results presented as moderate (P75 vs $\mathrm{P} 0$ ) or high (P95 vs $\mathrm{P} 0$ ) exposure to a pollutant

\begin{tabular}{|c|c|c|c|c|}
\hline \multirow[t]{2}{*}{ Exposure } & \multicolumn{2}{|l|}{ Dundee } & \multicolumn{2}{|l|}{ Perth } \\
\hline & $\begin{array}{l}\text { Moderate exposure } \\
\text { (P75 vs P0) }\end{array}$ & $\begin{array}{l}\text { High exposure } \\
\text { (P95 vs P0) }\end{array}$ & $\begin{array}{l}\text { Moderate exposure } \\
\text { (P75 vs P0) }\end{array}$ & $\begin{array}{l}\text { High exposure } \\
\text { (P95 vs P0) }\end{array}$ \\
\hline \multicolumn{5}{|l|}{ Lag 0} \\
\hline PM10 & $1.061(0.998-1.128)$ & $1.076(1.013-1.033)$ & $1.394(1.225-1.585)$ & $1.449(1.278-1.643)$ \\
\hline NOX & $1.941(1.785-2.111)$ & $2.057(1.889-2.240)$ & $1.589(1.460-1.729)$ & $1.707(1.565-1.862)$ \\
\hline $\mathrm{NO} 2$ & $1.816(1.638-2.014)$ & $1.894(1.706-2.103)$ & $1.528(1.383-1.688)$ & $1.650(1.488-1.829)$ \\
\hline NO & $1.901(1.763-2.051)$ & $1.942(1.802-2.094)$ & $1.552(1.440-1.673)$ & $1.654(1.530-1.789)$ \\
\hline \multicolumn{5}{|c|}{ Cumulative } \\
\hline PM10 & $0.998(0.946-1.054)$ & $0.979(0.927-1.033)$ & $0.999(0.893-1.118)$ & $0.988(0.886-1.101)$ \\
\hline NOX & $0.947(0.889-1.008)$ & $0.951(0.893-1.012)$ & $0.944(0.883-0.989)$ & $0.922(0.859-0.989)$ \\
\hline $\mathrm{NO} 2$ & $0.946(0.874-1.024)$ & $0.950(0.876-1.029)$ & $0.940(0.867-1.018)$ & $0.944(0.867-1.027)$ \\
\hline NO & $0.953(0.901-1.008)$ & $0.953(0.902-1.007)$ & $0.945(0.890-1.004)$ & $0.918(0.861-0.978)$ \\
\hline
\end{tabular}


Table 3 Adjusted risk ratios with 95\% confidence intervals for MI hospital admissions of patients under $>45$ years, in Dundee and Perth and exposure to pollutants. Lag 0 and cumulative risk (lag 0 5 days) given. Results presented as moderate (P75 vs P0) or high (P95 vs $\mathrm{P} 0$ ) exposure to a pollutant

\begin{tabular}{|c|c|c|c|c|}
\hline \multirow[t]{2}{*}{ Exposure } & \multicolumn{2}{|l|}{ Dundee } & \multicolumn{2}{|l|}{ Perth } \\
\hline & $\begin{array}{l}\text { Moderate exposure } \\
\text { (P75 vs P0) }\end{array}$ & $\begin{array}{l}\text { High exposure } \\
\text { (P95 vs P0) }\end{array}$ & $\begin{array}{l}\text { Moderate } \\
\text { exposure (P75 vs P0) }\end{array}$ & $\begin{array}{l}\text { High exposure } \\
\text { (P95 vs P0) }\end{array}$ \\
\hline \multicolumn{5}{|l|}{ Lag0 } \\
\hline PM10 & $1.048(0.917-1.198)$ & $1.055(0.922-1.067)$ & $1.158(0.885-1.514)$ & $1.164(0.895-1.512)$ \\
\hline NOX & $1.178(0.988-1.405)$ & $1.199(1.000-1.438)$ & $1.484(1.237-1.780)$ & $1.527(1.265-1.844)$ \\
\hline $\mathrm{NO} 2$ & $1.136(0.918-1.406)$ & $1.140(0.916-1.418)$ & $1.506(1.213-1.869)$ & $1.550(1.239-1.941)$ \\
\hline NO & $1.147(0.977-1.346)$ & $1.158(0.987-1.357)$ & $1.456(1.238-1.712)$ & $1.498(1.264-1.776)$ \\
\hline \multicolumn{5}{|c|}{ Cumulative } \\
\hline PM10 & $0.973(0.863-1.098)$ & $0.947(0.840-1.067)$ & $1.111(0.870-1.419)$ & $1.104(0.870-1.399)$ \\
\hline NOX & $0.907(0.786-1.048)$ & $0.886(0.767-1.023)$ & $1.031(0.887-1.204)$ & $1.031(0.882-1.204)$ \\
\hline $\mathrm{NO} 2$ & $0.926(0.773-1.107)$ & $0.928(0.775-1.111)$ & $1.030(0.861-1.232)$ & $1.023(0.848-1.234)$ \\
\hline $\mathrm{NO}$ & $0.902(0.792-1.027)$ & $0.890(0.783-1.011)$ & $1.013(0.885-1.160)$ & $1.012(0.879-1.165)$ \\
\hline
\end{tabular}

these results. We did not find a risk of increased hospital admissions for any admission type over the cumulative lag period. Furthermore, we did not find an association between pollution exposure and recorded deaths during the study period.

This work is novel in that other publications, showing similar adverse effects of pollution, report major cities with population counts in the millions (Dockery et al. 1993; Goeminne et al. 2018; Butland et al. 2017). This work adds to the literature by showing that smaller cities (population $50 \mathrm{k}-150 \mathrm{k}$ ) can still suffer significant, and measurable, adverse effects of air pollution. This is not well recognised with $98 \%$ of low emissions zones in the UK being in its large major cities (Department for Environment Food and Rural Affaires and Department of Transport 2020).

The health problems resulting from exposure to air pollution also have a high financial cost to society and, as shown by our results, our health services. In the UK, these NHS costs add up to more than $£ 20$ billion every year (Royal College of Physicians 2016). Vulnerable/disadvantaged people are prisoners of air pollution, as they live in its midst. It is surprising that local authorities do not seem to have connected social and health care costs with pollution and realised that the added cost spent on preventing/ameliorating pollution will pay for itself in terms of social and health care down the line (Holland 2014).

Air pollution, particularly from external sources, is today's "silent killer". And its silent nature means little action is being taken. Providing more evidence for links to ill-health will hopefully provide the Scottish Government with the incentive enforcing their regulation by law. However, until it is enforced downwards, Councils with many calls on finances will remain unwilling to act, and hospital admissions will continue to reflect this cavalier attitude. The Cleaner Air for Scotland Strategy has much to recommend it but lacks enforcement teeth (Scottish Government 2015).

In conclusion, this paper further shows a harmful effect of pollution on hospital admissions, in two relatively small cities. It adds further evidence of the harm of air pollution, even in
Table 4 Adjusted risk ratios with 95\% confidence intervals for $\mathrm{HF}$ hospital admissions of patients under $>45$ years, in Dundee and Perth and exposure to pollutants. Lag 0 and cumulative risk (lag 0 5 days) given. Results presented as moderate (P75 vs P0) or high (P95 vs P0) exposure to a pollutant

\begin{tabular}{|c|c|c|c|c|}
\hline \multirow[t]{2}{*}{ Exposure } & \multicolumn{2}{|l|}{ Dundee } & \multicolumn{2}{|l|}{ Perth } \\
\hline & $\begin{array}{l}\text { Moderate exposure } \\
\text { (P75 vs P0) }\end{array}$ & $\begin{array}{l}\text { High exposure } \\
\text { (P95 vs P0) }\end{array}$ & $\begin{array}{l}\text { Moderate exposure } \\
\text { (P75 vs P0) }\end{array}$ & $\begin{array}{l}\text { High exposure } \\
\text { (P95 vs P0) }\end{array}$ \\
\hline \multicolumn{5}{|l|}{ Lag0 } \\
\hline PM10 & $1.032(0.884-1.205)$ & $1.112(0.952-1.265)$ & $1.569(1.098-2.243)$ & $1.667(1.176-2.362)$ \\
\hline NOX & $1.960(1.580-2.430)$ & $2.117(1.701-2.634)$ & $1.772(1.389-2.262)$ & $1.867(1.456-2.394)$ \\
\hline $\mathrm{NO} 2$ & $1.933(1.480-2.524)$ & $2.057(1.571-2.692)$ & $1.583(1.191-2.104)$ & $1.693(1.261-2.274)$ \\
\hline NO & $1.885(1.552-2.288)$ & $1.929(1.591-2.338)$ & $1.689(1.361-2.096)$ & $1.752(1.402-2.190)$ \\
\hline \multicolumn{5}{|c|}{ Cumulative } \\
\hline PM10 & $1.086(0.944-1.249)$ & $1.101(0.958-1.265)$ & $0.956(0.700-1.306)$ & $0.981(0.725-1.327)$ \\
\hline NOX & $0.910(0.777-1.065)$ & $0.909(0.775-1.065)$ & $0.970(0.801-1.143)$ & $0.933(0.762-1.143)$ \\
\hline $\mathrm{NO} 2$ & $0.968(0.793-1.183)$ & $0.969(0.792-1.186)$ & $1.010(0.800-1.275)$ & $1.021(0.799-1.303)$ \\
\hline NO & $0.891(0.774-1.026)$ & $0.889(0.774-1.021)$ & $0.969(0.816-1.151)$ & $0.935(0.778-1.123)$ \\
\hline
\end{tabular}


smaller UK cities. It reminds us also that as clinicians we should be using all our skills to attenuate this problem, as the Royal College of Physicians and the Royal College of Paediatricians, UK (Royal College of Physicians 2016), tell us:

"When our patients are exposed to such a clear and avoidable cause of death, illness and disability, it is our duty as doctors to speak out".

Supplementary Information The online version contains supplementary material available at https://doi.org/10.1007/s11356-021-16544-0.

Acknowledgements Data linkage was provided by the Tayside Health Informatics Centre (HIC).

Availability of data and materials The datasets used and/or analysed during the current study are available from the corresponding author on reasonable request.

Author contribution JJFB wrote the protocol, obtained funding and wrote the first draft of the paper. CF contributed to the protocol, did the analyses and contributed to the paper. $\mathrm{BC}$ developed the statistical methods, oversaw their implementation and contributed to the paper. JC contributed to the concept and contributed to the paper.

Funding The project was funded by the Miller Bequest and by the TICR appeal.

\section{Declarations}

Ethics approval and consent to participate All data were anonymised such that the researchers had no access to patient information and the linkage was done in the Health Informatics Safe Haven. It was thus considered by the Institution's Research Governance Team that Caldicott Approval was sufficient to carry out this research.

\section{Consent for publication Not applicable}

Competing interests The authors declare no competing interests.

Open Access This article is licensed under a Creative Commons Attribution 4.0 International License, which permits use, sharing, adaptation, distribution and reproduction in any medium or format, as long as you give appropriate credit to the original author(s) and the source, provide a link to the Creative Commons licence, and indicate if changes were made. The images or other third party material in this article are included in the article's Creative Commons licence, unless indicated otherwise in a credit line to the material. If material is not included in the article's Creative Commons licence and your intended use is not permitted by statutory regulation or exceeds the permitted use, you will need to obtain permission directly from the copyright holder. To view a copy of this licence, visit http://creativecommons.org/licenses/by/4.0/.

\section{References}

Butland BK, Atkinson RW, Crichton S, Barratt B, Beevers S, Spiridou A, Hoang U, Kelly FJ, Wolfe CD (2017) Air pollution and the incidence of ischaemic and haemorrhagic stroke in the South London Stroke Register: a case-cross-over analysis. J Epidemiol Communtiy Health 71:707-712. https://doi.org/10.1136/jech2016-208025

Department for Environment Food and Rural Affaires and Department of Transport (2020) Clean Air Zone Framework: Principles for setting up Clean Air Zones in England. https://assets.publishing.service. gov.uk/government/uploads/system/uploads/attachment_data/file/ 863730/clean-air-zone-framework-feb2020.pdf.

Dockery DW, Pope CA, Xu X, Spengler JD, Ware JH, Fay ME, Ferris BG Jr, Speizer FE (1993) An association between air pollution and mortality in six U.S. Cities. N Engl J Med 329:1753-1759. https:// doi.org/10.1056/NEJM199312093292401

Eur-Lex (2008) Consolidated text: Directive 2008/50/EC of the European Parliament and of the Council of 21 May 2008 on ambient air quality and cleaner air for Europe. https:/eur-lex.europa.eu/eli/dir/2008/ 50/2015-09-18.

Goeminne PC, Cox B, Finch S, Loebinger MR, Bedi P, Hill AT, Fardon TC, de Hoogh K, Nawrot TS, Chalmers JD (2018) The impact of acute air pollution fluctuations on bronchiectasis pulmonary exacerbation: a case-crossover analysis. Eur Respir J 52:1702557. https:// doi.org/10.1183/13993003.02557-2017

Holland M (2014)Cost-benefit analysis of final policy scenarios for the EU Clean Air Package (corresponding to IIASA TSAP 7) Changing our future. Report to European Commission DG Environment. http://ec.europa.eu/environment/air/pdf/TSAP\%20CBA.pdf.

Landrigan PJ, Fuller R, Acosta NJR, Adeyi O, Arnold R, Basu N et al (2018) The Lancet Commission on pollution and health. Lancet 391: 462-512. https://doi.org/10.1016/S0140-6736(17)32345-0

National Records of Scotland (2020)Drug-related deaths in Scotland in 2019. https://www.nrscotland.gov.uk/files/statistics/drug-relateddeaths/2019/drug-related-deaths-19-pub.pdf.

Nawrot TS, Perez L, Künzli N, Munters E, Nemery B (2011) Public health importance of triggers of myocardial infarction: a comparative risk assessment. Lancet 377:732-740. https://doi.org/10.1016/ S0140-6736(10)62296-9

Office for National Statistics (2019) Deaths related to drug poisoning in England and Wales: 2018 registrations. https://www.ons.gov.uk/ peoplepopulationandcommunity/birthsdeathsandmarriages/deaths/ bulletins/deathsrelated todrugpoisoninginenglandandwales/ 2018registrations.

Royal College of Physicians (2016) Every breath we take: the lifelong impact of air pollution. This report from the RCP and the RCPCH examines the impact of exposure to air pollution across the course of a lifetime. https://www.rcplondon.ac.uk/projects/outputs/everybreath-we-take-lifelong-impact-air-pollution. .

Scottish Government (2015) Cleaner Air For Scotland The Road To A Healthier Future. https://www.gov.scot/publications/cleaner-airscotland-road-healthier-future/.

Scottish Government (2018) Homicide in Scotland 2017-2018: statistics. https://www.gov.scot/publications/homicide-scotland-2017-18/ pages $/ 4 /$.

Statista (2020) England, Wales: homicides 2002-2019. https://www. statista.com/statistics/283093/homicides-in-the-uk/.

World Health Organization Europe (2006) Air Quality Guidelines Global Update 2005. https://www.euro.who.int/_data/assets/pdf_file/ 0005/78638/E90038.pdf.

Ye X, Wolff R, Yu W, Vaneckova P, Pan X, Tong S (2012) Ambient temperature and morbidity: a review of epidemiological evidence. Environ Health Perspect 120:19-28. https://doi.org/10.1289/ehp. 1003198

Publisher's note Springer Nature remains neutral with regard to jurisdictional claims in published maps and institutional affiliations. 